\title{
Long-term impact of lipofilling in hybrid breast reconstruction: retrospective analysis of two cohorts
}

\author{
Sarah Calabrese ${ }^{1} \cdot$ Nicola Zingaretti $^{2}$ (D - Francesco De Francesco ${ }^{3} \cdot$ Michele Riccio $^{3}$ - Fabrizio De Biasio ${ }^{2}$. \\ Samuele Massarut ${ }^{4} \cdot$ Daria Almesberger $^{4}$. Pier Camillo Parodi ${ }^{2}$
}

Received: 15 May 2019 / Accepted: 4 September 2019 / Published online: 26 November 2019

(C) The Author(s) 2019

\begin{abstract}
Lipofilling has recently gained popularity as a tool in primary treatment of breast cancer, and its association with two-stage implant breast reconstruction is considered as standard treatment in many centers. However, no data are available about the longterm results of the association of lipofilling in combination with expander-implant reconstruction. A retrospective analysis was conducted on patients treated between January 2010 and December 2014. Two groups were compared. Group 1 had a standard expander-implant two-stage reconstruction. Group 2 underwent hybrid breast reconstruction (HBR). Patient characteristics, hospitalization, outcomes, reoperation details, outpatient visits, and evaluation questionnaires were taken into consideration. Intergroup comparison was performed using Wilcoxon Mann-Whitney $U$ test and Pearson's chi-square test or Fisher's exact test for categorical variables. Two hundred fourteen patients were evaluated: 130 patients in group 1 and 84 patients in group 2 . Group 2 showed significant benefits over group 1 in terms of capsular contracture rate, breast pain, and displacement/rotation of the implant $(p=0.005)$. The HBR protocol is associated with lower rate of capsular contracture, less breast pain at long follow-up times, and lower overall rates of revision surgery compared to standard expander-implant reconstruction. A specific cost analysis will help further clarify the advantages of this protocol over a standard procedure.

Level of Evidence: Level III, risk/prognostic, therapeutic study.
\end{abstract}

Keywords Autologous fat graft $\cdot$ Breast surgery $\cdot$ Capsular contracture $\cdot$ Hybrid breast reconstruction

\section{Introduction}

Lipofilling is one of the most investigated topics in Plastic Surgery in recent decades, although the use of adipose tissue for reconstruction purposes can be traced back to studies published a century ago. Neuber and Guthrie, respectively, first

Nicola Zingaretti

zingarettin@gmail.com

1 Department of Plastic and Reconstructive Surgery, Spedali Civili di Brescia, Brescia, Italy

2 Clinic of Plastic and Reconstructive Surgery, Academic Hospital of Udine, Department of Medical Area (DAME), University of Udine, c/o Ospedale "S. Maria della Misericordia", piazzale santa maria della misericordia 15, 33100 Udine, Italy

3 SODC Chirurgia Ricostruttiva e Chirurgia della Mano, AOU Ospedali Riuniti, Ancona, Italy

4 Breast Surgery Unit, CRO, National Cancer Institute, Aviano, Italy described the use of adipose tissue to restore body shape after tuberculosis and to correct depressed areas after mastoid surgery $[1,2]$. Thanks to the introduction of liposuction described by Fisher in 1974, 20 years later, the term lipofilling is now in common use [3]; this is also due to the pivotal work by Roddi et al. on correction of progressive hemifacial atrophy [4]. Since then, lipofilling has gained widespread popularity, and its use in breast surgery has become a standard procedure [5]. Fat grafting has been proposed as a tool to improve the outcome for capsular contracture after breast implant reconstruction [6-9]. Even in breast implant augmentation, lipofilling now has a well-recognized role [10, 11]. A large number of studies have investigated the technique of fat grafting, its safety in breast surgery, the variations offered by the different types of harvesting techniques, optimal donor site, device employed, elaboration of adipose tissue, recipient site preparation, and timing of surgery [12-20]. Many reviews are available comparing dozens of studies, analyzing every step of the lipofilling procedure, in order to find a standard method to ensure the best graft-taking rate [21-23]. 


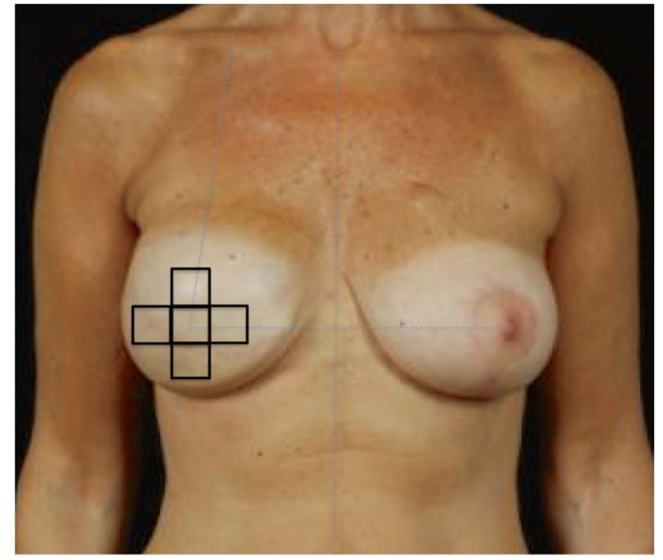

Fig. 1 Thickness of mastectomy flaps was evaluated with pinch test and ultrasound in five different areas of the breast: the first template is over the central quadrant (nipple-areola complex area) and other four are circumferential. The dimension of each template is $4 \times 4 \mathrm{~cm}$

Fat grafting leads to improved outcomes in breast implant surgery $[24,25]$. Its use on secondary cases can show a beneficial effect after the complication has been assessed in detail, and the introduction of further surgical steps (lipofilling) at the time of expansion can reduce unfavorable outcomes.

The aim of our study is to evaluate long-term results of a "hybrid breast reconstruction" (HBR) protocol [26], wherein fat grafting is performed during the course of the expander/ implant reconstruction. The main object of the study is to determine the rate of capsular contracture. Secondary outcomes were analysis of postoperative complications, reoperations performed or refused by the patient, and the assessment of the esthetic result.

\section{Materials and methods}

A retrospective study was conducted taking into consideration all surgical breast reconstructive procedures with two-stage expander/implant reconstruction. The population was divided into two cohorts. Group 1 includes patients who underwent expander/implant standard reconstruction and represents the control group. Group 2 includes patients who underwent the HBR protocol. Criteria for exclusion were chronic liver disease, coagulopathies, and/or anticoagulant therapy, patients who underwent mammary reconstruction after trauma or congenital disease, and patients lost to follow-up.

All procedures performed were in accordance with the ethical standards of the Institutional Committee and with the 1964 Helsinki declaration and its later amendments. Written informed consent was obtained from all patients. This study is in line with the STROCSS criteria [27].

\section{Patients and methods}

A retrospective chart review was performed for 84 consecutive postmastectomy patients who underwent secondary breast reconstruction from January 2010 to December
Fig. 2 a-d Preoperative pictures of a 42-year-old patient who underwent nipple sparing mastectomy and expander immediate reconstruction. e Ultrasound evaluation of the subcutaneous tissue with $1.07 \mathrm{~cm}$ measurement. f-i Postoperative result after 24 months from the second surgical step of expander/implant exchange procedure. The patient had one lipofilling session during the latter surgery

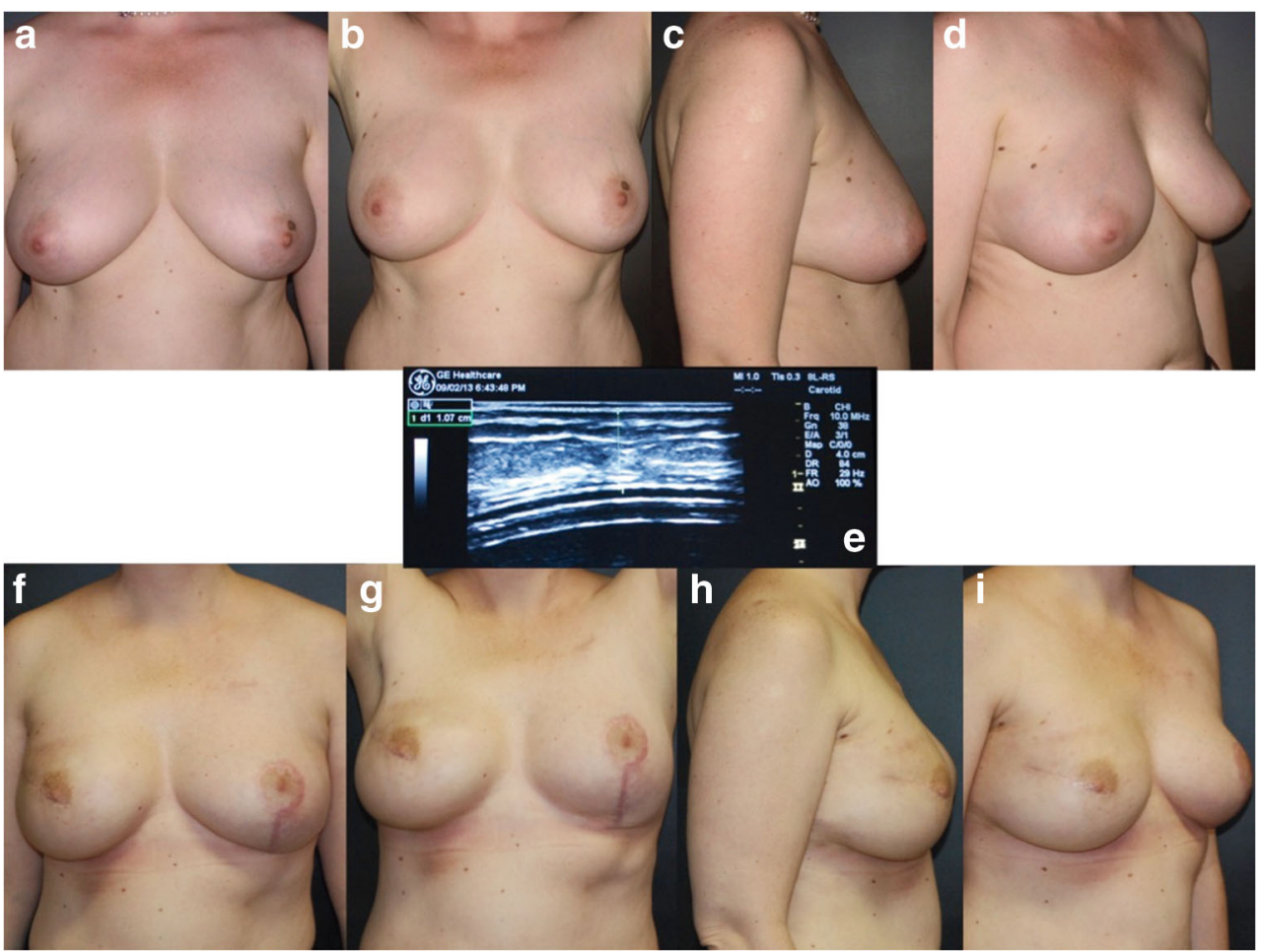


2014 at our institute. Our study population (group 2) was aged between 35 and 65 years old, who underwent the same surgical procedure (unilateral mastectomy, immediate reconstruction with a tissue expander, and replacement with definitive implant), with similar follow-up and the same type of therapeutic approach in terms of complementary therapies.
After unilateral mastectomy and immediate reconstruction with an expander, these patients were submitted to one to three serial deflation-lipofilling procedures. Positioning of a definitive prosthesis was performed during the last lipofilling session.
Table1 Pati ent demographics, breast cancer histology, frequency of relapses, metastasis and second cancer, comorbidities, breast implants employed in reconstruction, procedures for symmetrization of the contralateral breast

\begin{tabular}{|c|c|c|c|c|c|}
\hline & Group 1 & & Group 2 & & \\
\hline Patient age (average) (years) & 57 & & 55 & & \\
\hline \multirow[t]{2}{*}{ Follow-up (average) (months) } & 36.15 & & 32.91 & & \\
\hline & $\begin{array}{l}\text { No. } \\
\text { patients } \\
\text { group } 1\end{array}$ & $\%$ group 1 & $\begin{array}{l}\text { No. } \\
\text { patients } \\
\text { group } 2\end{array}$ & $\%$ group 2 & $p$ \\
\hline \multicolumn{6}{|l|}{ Breast cancer histology } \\
\hline - CaDI & 84 & $65.12 \%$ & 59 & $71.95 \%$ & \\
\hline - DCIS & 11 & $8.53 \%$ & 5 & $6.10 \%$ & \\
\hline - DCIN & 11 & $8.53 \%$ & 5 & $6.10 \%$ & 0.475 \\
\hline$-\mathrm{CaLI}$ & 10 & $7.75 \%$ & 9 & $10.98 \%$ & \\
\hline - CaDLI & 9 & $6.98 \%$ & 3 & $3.66 \%$ & \\
\hline - Other & 4 & $3.10 \%$ & 1 & $1.22 \%$ & \\
\hline Relapses/metastasis & 8 & $6.15 \%$ & 3 & $3.57 \%$ & 0.403 \\
\hline Second cancer & 3 & $2.31 \%$ & 4 & $4.76 \%$ & 0.324 \\
\hline Radiotherapy & 16 & $12.31 \%$ & 22 & $26.19 \%$ & $0.009^{*}$ \\
\hline Chemiotherapy & 78 & $60 \%$ & 53 & $63.10 \%$ & 0.650 \\
\hline Ormonotherapy & 101 & $77.69 \%$ & 68 & $80.95 \%$ & 0.567 \\
\hline \multicolumn{6}{|l|}{ Comorbidities } \\
\hline Smoker & 30 & $23.08 \%$ & 10 & $11.09 \%$ & $0.040 *$ \\
\hline Diabetes & 3 & $2.31 \%$ & 5 & $5.95 \%$ & 0.169 \\
\hline Rheumatic disease & 6 & $4.62 \%$ & 5 & $6.02 \%$ & 0.650 \\
\hline Obesity & 31 & $23.85 \%$ & 20 & $24.10 \%$ & 0.966 \\
\hline Other diseases & 72 & $55.38 \%$ & 44 & $52.38 \%$ & 0.666 \\
\hline \multicolumn{6}{|l|}{ Type of surgical procedure } \\
\hline Simplex mastectomy & 107 & $82.31 \%$ & 65 & 77.38 & 0.844 \\
\hline Skin sparing mastectomy & 13 & $10 \%$ & 11 & $13.10 \%$ & \\
\hline Nipple sparing mastectomy & 9 & $6.92 \%$ & 7 & $8.33 \%$ & \\
\hline Skin reducing mastectomy & 1 & $0.77 \%$ & 1 & $1.19 \%$ & \\
\hline Delayed reconstruction & 18 & $13.85 \%$ & 5 & $5.95 \%$ & 0.068 \\
\hline $\begin{array}{l}\text { Contralateral breast } \\
\text { symmetrization }\end{array}$ & 10 & $7.75 \%$ & 4 & $4.88 \%$ & 0.457 \\
\hline Prophylactic mastectomy & 2 & $1.54 \%$ & 2 & $2.38 \%$ & 0.656 \\
\hline \multicolumn{6}{|l|}{ Type of prosthesis } \\
\hline Allergan & 4 & $3.08 \%$ & 27 & $32.14 \%$ & $<0.0001$ \\
\hline Mentor & 126 & $96.92 \%$ & 52 & $61.90 \%$ & \\
\hline Polytech & 0 & 0 & 5 & $5.95 \%$ & \\
\hline \multicolumn{6}{|c|}{ Procedures for symmetrisation of the contralateral breast } \\
\hline Reductive mastoplasty & 14 & $16.28 \%$ & 9 & $17.31 \%$ & 0.654 \\
\hline Augmentation mammoplasty & 30 & $34.88 \%$ & 21 & $40.38 \%$ & \\
\hline Mastopexy & 40 & $46.51 \%$ & 20 & $38.46 \%$ & \\
\hline Autologous reconstruction & 2 & $2.33 \%$ & 1 & $1.92 \%$ & \\
\hline Lipofilling & 0 & 0 & 1 & $1.92 \%$ & \\
\hline
\end{tabular}

$* p<0.05$ was accepted as the level of statistical significance 
Patients were assessed for the thickness of mastectomy flaps and the presence of radiotherapy. For mastectomy skin flap thickness $<0.5 \mathrm{~cm}$ and/or those subjected to radiotherapy, patients were submitted to two lipofilling sessions before replacement of the expander. Smoking habit was not taken into account for patient selection.

For this study, a group of 130 subjects who underwent the standard expander/implant reconstruction was selected as the control population (group 1).

All patients underwent surgery by the senior author of this study (P.C.P). Patients were examined on postoperative days 3,7 , and 14, and follow-up visits were scheduled at 1 month and every 6 months postoperatively. Clinical evaluation of the reconstruction and patient satisfaction were recorded. Assessment of capsular contracture was based on Baker's modified classification [28].

\section{Preoperative planning and HBR protocol}

The first surgical step was the same for all patients as they underwent mastectomy and reconstruction with a breast tissue expander. Mastectomy skin flap thickness was determined at 3 months postoperative at the end of the outpatient expansion procedures by a pinch test (by a skinfold caliper) and ultrasound [29]. Five regions of the breast were identified with a template, and measurements were recorded in the same area in all participants with both measurement devices (see Fig. 1).

Pinch caliper measurements In the middle box of each template, a skin caliper (Gima, Gessate, Italy) was used to measure subcutaneous fat thickness. One measurement for each was taken in each middle box, for a total of 5 measurements. The clinician (S.C.) taking the skinfold caliper measurement was right-hand dominant, so with her left thumb and forefinger she lifted the skin away from the muscle and pinched it together. With her right hand, she placed the jaws of the skinfold caliper inferior to the pinch and completely released her thumb from the handle. The reading was recorded after the first rapid fall on the dial.

The fat thickness recorded by the skinfold caliper was divided in half to represent the subcutaneous fat layer over the muscle.

Ultrasound imaging Ultrasound imaging (GE Heathcare Logiq F8, Waukesha, WI) was used to measure subcutaneous fat thickness in each middle box. An 8-MHz linear array was used while capturing the image in B-mode. Ultrasound gel was applied liberally to the center of the template before placing the transducer on the skin. After a clear image was identified, the image was saved.
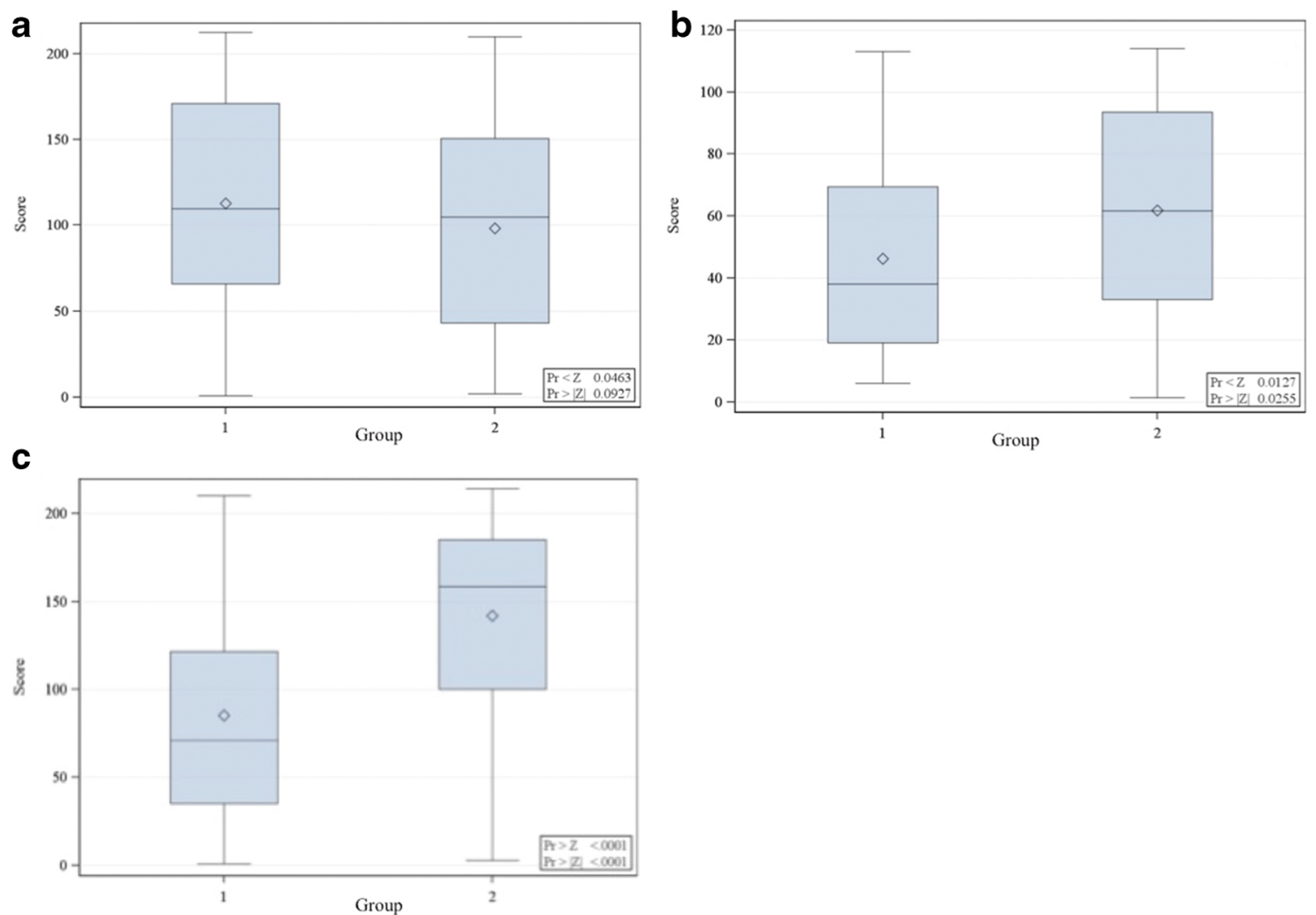

Fig. 3 Distribution of Wilcoxon scores for breast prosthesis volume (a), quantity of fat infiltration (b), and duration of intervention (replacement of the breast tissue expander with permanent implant, in minutes) (c) 
The images were labeled with the participant number and site (upper, central, left, right, below) of measurement. On a subsequent day, the clinician (S.C.) who obtained the images opened the saved images and measured subcutaneous fat thickness using the measurement tool.

All the patients who were randomly selected to have HBR protocol accepted it, and signed informed consent was obtained from all.

Depending on the skin thickness and previous radiotherapy, an average of 1 to 3 deflation-lipofilling sessions were programmed (see Fig. 2a-i). If a single lipofilling procedure was necessary, it was performed at the time of expander/ implant exchange procedure. If multiple deflation-lipofilling sessions were scheduled, they were performed after final filling of the tissue expander. The fat was positioned at the level of the mastectomy flap, between skin and peri-prosthetic capsule. Deflation was conducted to be $10 \mathrm{cc}$ superior to the total amount of fat injected.

If we noticed the skin over the breast area was too stretched after the fat grafting session, we would remove a greater quantity of saline solution from the breast expander. Deflationlipofilling sessions were scheduled every 3 months.

In all patients, anatomical textured silicone gel implants were placed in the subpectoral pocket. All patients received perioperative antibiotic prophylaxis (cephazolin $2 \mathrm{~g}$, intravenous injection, $30 \mathrm{~min}$ before the beginning of surgery).

\section{Questionnaire}

Patients were asked to fill in the postoperative BREAST-Q reconstruction questionnaire [30-32] to evaluate the outcomes. The BREAST-Q reconstruction module has the following scales: satisfaction with breasts, satisfaction with implants, psychosocial well-being, sexual well-being, physical well-being. We administered the questionnaire electronically 2 years after surgery.

We compared patient questionnaire scores (group 1 vs group 2) to determine if there was a significant improvement in esthetic outcomes between the groups.

\section{Statistical analysis}

Intergroup comparison was performed using a Mann-Whitney $U$ test and Pearson's chi-square test or Fisher's exact test for categorical variables. A $p<0.05$ was accepted as the level of statistical significance.

The chi-squared test is used to compare the distribution of the Breast-Q items in group 1 and 2. $p<0.01$ was accepted as the level of statistical significance.

Data were analyzed using SPSS version 22.0 (IBM statistics for Windows version 22, IBM Corporation, Armonk, NY, USA).

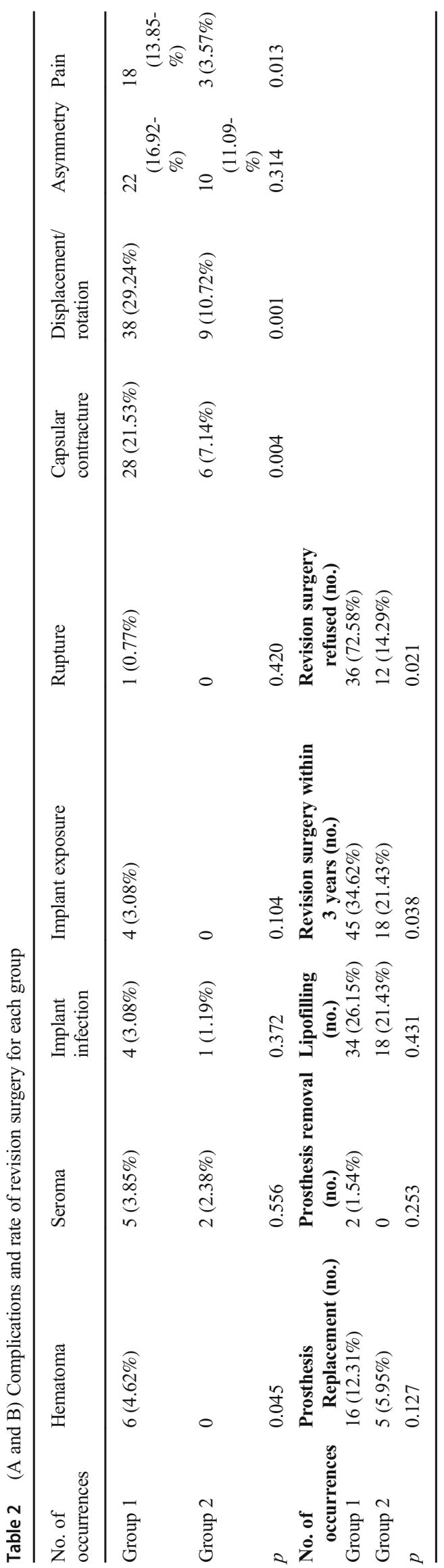




\section{Results}

Patient demographics are reported in Table 1. The mean age of patients was 57 years for group 1 and 55 years for group 2 . Patient follow-up was considered in months, with an average of 36.15 for group 1 (range 12-60 months) and 32.91 for group 2 (range 12-50 months). The clinical history of these patients included at least two operations. The first was mastectomy; 191 patients $(89.25 \%)$ underwent immediate reconstruction with a tissue expander. The second step included expander replacement by definitive implant; one to three deflation-lipofilling sessions were scheduled during this second surgical phase for patients in group 2. With regard to delayed breast reconstruction, it was more frequent in group $1(14 \%)$ compared to group 2 (6\%). Radiotherapy was administrated to 16 (12.3\%) patients in group 1 and $22(26.19 \%)$ patients in group 2.

Tissue expanders were left in place for a mean of 15 weeks (range 13-19), and replacement with the final prosthesis was performed after a mean of 19 weeks (range 17-25). The mean volume of the definitive prosthesis was 438 cc (range 150$800 \mathrm{cc}$ ): although there were no statistically significant differences between groups $(p>0.05)$, larger volume prostheses were used in group 1 (Fig. 3a).

All patients in group 2 had at least one lipofilling session at the time of removal of the expander. Moreover, nine patients had a total of two lipofilling sessions and six patients had a total of three lipofilling sessions.

Thirty-four patients (26\%) from group 1 underwent lipofilling as a secondary procedure. There was one session for 29 patients, two sessions for four patients, and three sessions in one patient.

The average quantity of adipose tissue infiltrated for both groups was $88.27 \mathrm{cc}$ (85.26 cc for group 1 and $89.5 \mathrm{cc}$ for group 2).

There was a significant difference between groups $(p>0.05)$ regarding the total amount of adipose tissue infiltrated: there was more fat infiltration in group 2 (Fig. 3b).
Postoperative complications (Table 2) included 6 hematomas for group 1 ( $p=0.045), 7$ seromas ( 5 for group 1 and 2 for group 2), 5 implant infections (4 for group 1 and 1 for group 2 ), and one case of breast prosthesis rupture (group 1). There were no significant differences between groups regarding asymmetry $(p>0.05)$. Incidence of capsular contracture in two groups was the most important endpoint of our study for which a significant difference between groups was found $(p=0.004)$. Twenty-eight patients developed capsular contracture in group $1(21.53 \%)$ compared to 6 in group 2 $(7.14 \%)$.

Thirty-eight patients in group $1(29.24 \%)$ and $9(10.72 \%)$ patients in group 2 presented displacement/rotation of the implant $(p=0.001)$.

The difference in the onset of breast pain between groups was statistically significant ( $p=0.013$ ): it involved 18 patients in group 1 and 3 patients in group 2 .

Outcomes were similar regarding the reoperation rate: as shown in Table 2, there were no significant differences between groups regarding the number of prosthesis replacements $(p=0.127)$ and prosthesis removals $(p=0.253)$.

For group 2, we considered fat grafting procedures not included in HBR protocol, but which were conducted as secondary procedures. We did not observe any significant difference between the experimental and control group for secondary fat grafting procedures $(p=0.431)$. Refusal of reoperation between groups was statistically significant.

To understand the difference in costs regarding the reconstructive protocol in groups 1 and 2, we assessed surgical time in the operating room, number of hospitalization days, number of interventions required for each patient, and number of outpatient department visits.

With regard to surgical time, the hybrid breast reconstruction was longer than the surgical procedure in the control population $(p<0.0001)$. This indicates that HBR was more expensive compared with the replacement of the breast expander with a permanent implant standard procedure (Fig. $3 \mathrm{c}$ ).

However, there were no significant differences between groups regarding the number of definitive prostheses and breast tissue expanders used, number of admissions to

Table 3 Costs of breast reconstruction procedures for each group

\begin{tabular}{lllllll}
\hline & $\begin{array}{l}\text { Admission } \\
\text { in } \\
\text { hospital (no.) }\end{array}$ & $\begin{array}{l}\text { Operation } \\
\text { (no.) }\end{array}$ & $\begin{array}{l}\text { Hospitalization } \\
\text { days (no.)* }\end{array}$ & $\begin{array}{l}\text { Hospitalization } \\
\text { days (no.)** }\end{array}$ & $\begin{array}{l}\text { Total days in the } \\
\text { hospital (no.) }\end{array}$ & $\begin{array}{l}\text { Outpatient } \\
\text { department } \\
\text { visits (no.) }\end{array}$ \\
\hline Group 1 & 1.44 & 1.47 & 3.94 & 1.67 & 4.85 & 6,9 \\
Group 2 & 2 & 2 & 3 & 2 & 5.07 & 6 \\
$p$ & 0.097 & 0.170 & 0.009 & 0.252 & 0.562 & 0.449 \\
\hline
\end{tabular}

*Days in the hospital for the first operation (mastectomy and immediate reconstruction with an expander)

**Days in the hospital for the second operation (the replacement of the expander with permanent implant \pm lipofilling) 
Table 4 BREAST-Q postoperative module in patients following expander/implant standard 456 reconstruction (group 1) or HBR protocol (group 2)

\begin{tabular}{|c|c|c|c|}
\hline Question & Post (group 1) & Post (group 2) & $p$ (2 years) \\
\hline No. $(\%)$ & 87 & 64 & - \\
\hline \multicolumn{4}{|l|}{ Satisfaction with breasts } \\
\hline How you look in the mirror clothed? & $55(63)$ & $46(71)$ & 0.34 \\
\hline The shape of your reconstructed breast(s) when you are wearing a bra? & $63(72)$ & $50(78)$ & 0.54 \\
\hline How normal you feel in your clothes? & $67(77)$ & $52(81)$ & 0.66 \\
\hline The size of your reconstructed breast(s)? & $74(85)$ & $57(89)$ & 0.63 \\
\hline Being able to wear clothing that is more fitted? & $64(74)$ & $51(80)$ & 0.49 \\
\hline How your breasts are lined up in relation to each other? & $63(72)$ & $58(90)$ & $0.01 *$ \\
\hline How comfortably your bras fit? & $67(77)$ & $55(86)$ & 0.24 \\
\hline The softness of your reconstructed breast(s)? & $46(53)$ & $54(84)$ & $0.0001 *$ \\
\hline How equal in size your breasts are to each other? & $70(80)$ & $58(90)$ & 0.13 \\
\hline How natural your reconstructed breast(s) looks? & $47(64)$ & $45(70)$ & 0.04 \\
\hline How naturally your reconstructed breast(s) sits/hangs? & $44(51)$ & $56(88)$ & $0.0001 *$ \\
\hline How your reconstructed breast(s) feels to touch? & $48(55)$ & $57(89)$ & $0.0001 *$ \\
\hline How much your reconstructed breast(s) feel like a natural part of your body? & $34(39)$ & $43(68)$ & $0.0012 *$ \\
\hline How closely matched (similar) your breasts are to each other? & $47(54)$ & $39(60)$ & 0.72 \\
\hline How you look in the mirror unclothed? & $39(44)$ & $35(54)$ & 0.30 \\
\hline \multicolumn{4}{|l|}{ Satisfaction with implants } \\
\hline The amount of rippling (wrinkling) of your implant(s) that you can see? & $51(59)$ & $57(89)$ & $0.0001 *$ \\
\hline The amount of rippling (wrinkling) of your implant(s) that you can feel? & $47(54)$ & $58(90)$ & $0.0001 *$ \\
\hline \multicolumn{4}{|l|}{ Psychosocial well-being } \\
\hline Confident in a social setting? & $71(82)$ & $54(84)$ & 0.82 \\
\hline Emotionally able to do the things that you want to do? & $67(77)$ & $48(75)$ & 0.77 \\
\hline Emotionally healthy? & $72(82)$ & $54(84)$ & 0.79 \\
\hline Of equal worth to other women? & $70(80)$ & $49(77)$ & 0.56 \\
\hline Self-confident? & $75(86)$ & $53(83)$ & 0.56 \\
\hline Feminine in your clothes? & $78(89)$ & $58(90)$ & 0.84 \\
\hline Accepting of your body? & $77(88)$ & $58(90)$ & 0.67 \\
\hline Normal? & $77(88)$ & $55(86)$ & 0.63 \\
\hline Like other women? & $78(89)$ & $58(90)$ & 0.84 \\
\hline Attractive? & $63(72)$ & $43(68)$ & 0.48 \\
\hline \multicolumn{4}{|l|}{ Sexual well-being } \\
\hline Sexually attractive in your clothes? & $64(74)$ & $46(71)$ & 0.81 \\
\hline Comfortable/at ease during sexual activity? & $55(63)$ & $39(60)$ & 0.77 \\
\hline Confident sexually? & $63(72)$ & $45(70)$ & 0.77 \\
\hline Satisfied with your sex-life? & $64(73)$ & $48(75)$ & 0.84 \\
\hline Confident sexually about how your breast area looks when unclothed? & $47(54)$ & $36(56)$ & 0.78 \\
\hline Sexually attractive when unclothed? & $39(44)$ & $36(55)$ & 0.16 \\
\hline \multicolumn{4}{|l|}{ Physical well-being } \\
\hline Neck pain? & $34(39)$ & $23(35)$ & 0.69 \\
\hline Upper back pain? & $33(38)$ & $23(35)$ & 0.80 \\
\hline Shoulder pain? & $33(38)$ & $24(37)$ & 0.95 \\
\hline Arm pain? & $25(29)$ & $17(27)$ & 0.76 \\
\hline Rib pain? & $40(45)$ & $21(32)$ & 0.10 \\
\hline Pain in the muscles of your chest? & $57(65)$ & $21(32)$ & $0.0001 *$ \\
\hline Difficulty lifting or moving your arms? & $25(29)$ & $17(27)$ & 0.76 \\
\hline Difficulty sleeping because of discomfort in your breast area? & $39(44)$ & $21(32)$ & 0.13 \\
\hline Tightness in your breast area? & $51(59)$ & $23(35)$ & $0.005 *$ \\
\hline Pulling in your breast area? & $50(57)$ & $23(35)$ & $0.008 *$ \\
\hline
\end{tabular}


Table 4 (continued)

\begin{tabular}{|c|c|c|c|}
\hline Question & Post (group 1) & Post (group 2) & $p(2$ years $)$ \\
\hline Nagging feeling in your breast area? & $50(57)$ & $23(35)$ & $0.008^{*}$ \\
\hline Tenderness in your breast area? & $39(44)$ & $30(47)$ & 0.80 \\
\hline Sharp pains in your breast area? & $57(65)$ & $20(31)$ & $0.0001 *$ \\
\hline Shooting pains in your breast area? & $63(72)$ & $29(46)$ & $0.0007 *$ \\
\hline Aching feeling in your breast area? & $62(71)$ & $23(35)$ & $0.0001 *$ \\
\hline Throbbing feeling in your breast area? & $64(73)$ & $26(41)$ & $0.0001^{*}$ \\
\hline
\end{tabular}

Raw score $\geq 4$

${ }^{*} p<0.01$ was accepted as the level of statistical significance

hospital, number of interventions required for each patient, number of hospitalization days, or number of outpatient department visits (Table 3).

Eighty-six patients of group 1 and sixty-four of group 2 completed BREAST-Q surveys, with a response rate of $66 \%$ for group 1 and $78 \%$ for group 2 .

The answers of the patients to the BREAST-Q and the statistical analysis are shown in Table 4 and Fig. 4a, b. After further analysis of the questionnaire, we observed that patients in group 2 obtained significantly better postoperative results than patients from group 1 (control) regarding the following items: the reconstructed breast softness, symmetry (breasts of equal size relative to the other), reconstructed breast look and touch, amount of implant rippling perceived by the patients, and physical well-being about chest and upper body.

\section{Discussion}

A number of studies have been carried out on the introduction of lipofilling as a preliminary step in breast reconstruction for patients undergoing mastectomy and radiotherapy [33, 34]. Several authors have proposed the use of lipofilling on expanders, limiting this indication to patients who received postmastectomy radiotherapy (PMRT) [35]. In 2008, Sarfati et al. published an analysis of 28 patients who underwent multiple lipofilling sessions to prepare the thoracic region for breast implant reconstruction [36]. Panettiere et al., in 2009, were the first to propose fat grafting as a surgical tool for improving outcomes of breast implant reconstruction after radiotherapy in a case-control study. Improved esthetic and functional result were reported, together with a reduced complication rate, in the study group [36]. Between 2010 and 2012, Salgarello et al. published their LIPOBED protocol [34, 37].

In 2010, Serra-Renom et al. [38] introduced two fat grafting sessions during two-stage breast implant reconstruction. No statistical analysis was conducted, but they reported a lower rate of capsular contraction.

In 2013, Ribuffo et al. published the Cagliari University Hospital (CUH) protocol for breast reconstruction after
PMRT. This was a case control study with no report of complications in the study group [35, 39].

The concept of lipofilling has evolved as a primary tool in breast reconstruction. Deflation-lipofilling sessions are conducted to prevent complications during the reconstructive step, limiting the onset of postoperative complications. As other authors promote the use of polyurethane implants as a first step in breast reconstruction to reduce complication rates [40, 41] and not only as a rescue tool after a failure, in the same way, the present study investigated the beneficial effect of fat grafting as a part of the standard two-stage breast implant reconstruction for all postmastectomy patients in order to reduce overall capsular contracture and improve the esthetic result.

This is the first report of 84 patients, a case-control study, with a mean follow-up time of 34.87 months. Statistical analysis showed that fat grafting may have a role in reducing the capsular contracture rate. One to three more surgeries per patient should be costeffective for a Plastic Surgery Department. Operative time at the moment of expander/implant exchange has been reported to be significantly longer for HBR. However, the number of hospitalizations, surgical procedures, and outpatient sessions did not show any significant differences.

The beneficial effect of deflation-lipofilling procedures, despite adjunctive costs, was evaluated by Sommeling et al. and Stillaert et al. [42, 43]. The latter study included the removal of the expander at the end of the programmed reconstruction, without any implant positioning, in order to guarantee a total autologous reconstruction. The same conclusion was reached by the study by Fabiocchi et al. [44].

The study by Sommeling et al. was detailed and endoscopic imaging was used to show the capsular vascular plexus, which is related to increased survival of adipose tissue. However, that study involved a limited number of patients, without a control group and with 9 to 29 months of follow-up.

Nava et al. reported on a large series of 350 patients treated with lipofilling and implants. He reported detailed algorithms 
for the surgical pathway to follow regarding the patient BMI. Although in that study there is no study description, statistical analysis, or detailed results [45].
Since Rigotti's work on the effect of adipose tissue on radiated breast [46], many attempts have been made to further confirm the advantages of fat grafting procedures. Indeed, the

a
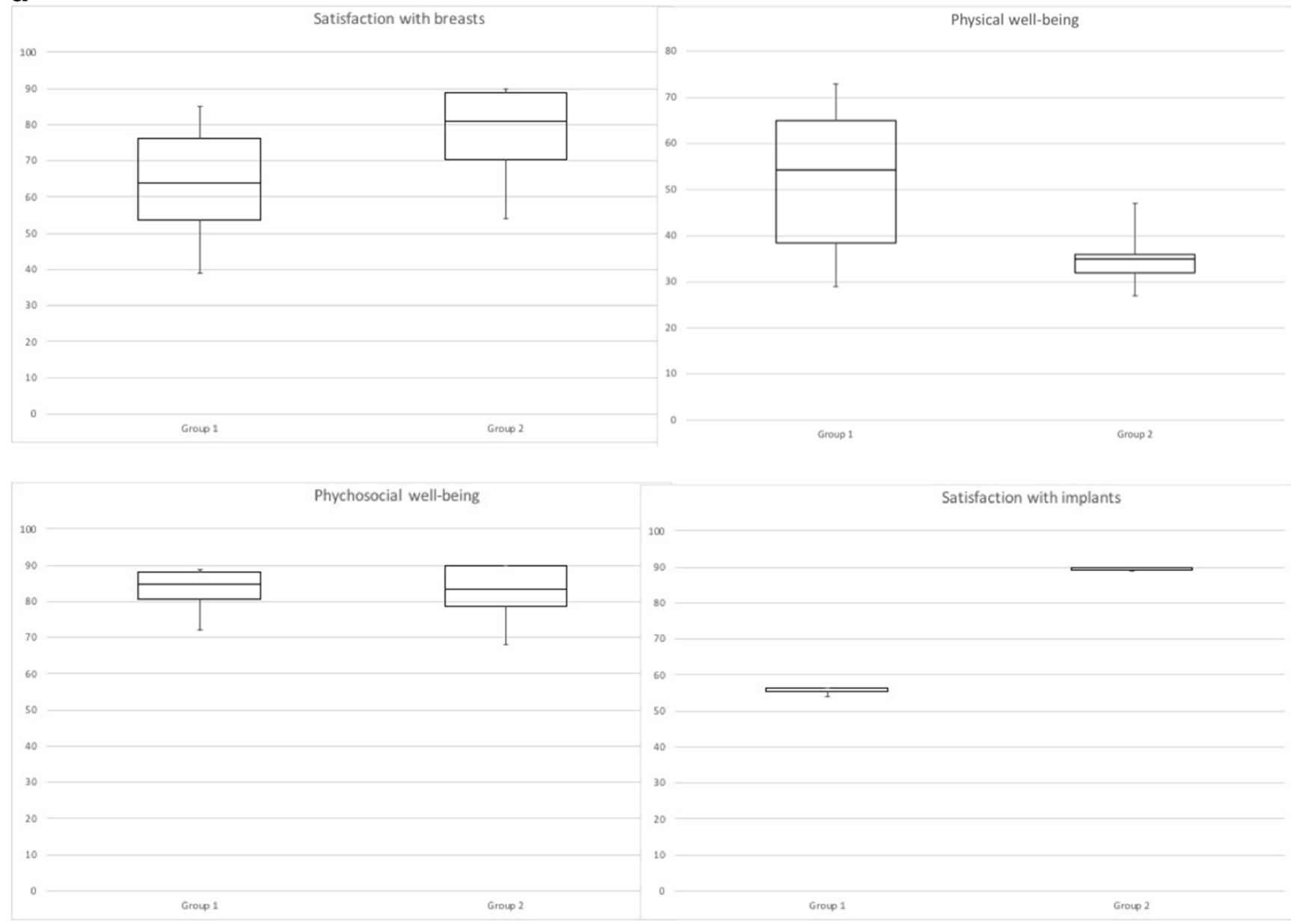

b

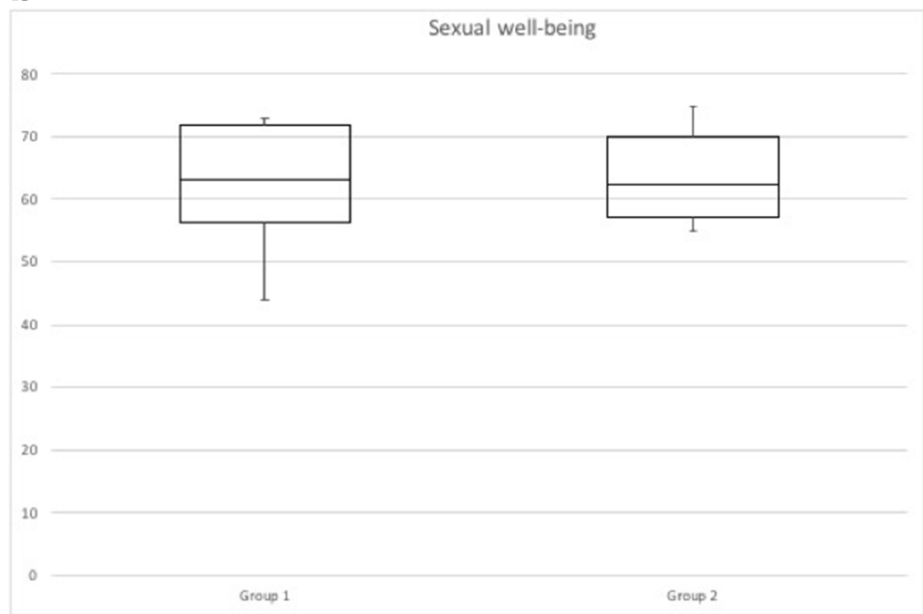

Fig. 4 a, b Box plot of estimated correlation values by Breast-Q domains. Within each box, horizontal middle lines denote median values; boxes extend from the 25th to the 75th percentile of each group's distribution of

values; vertical extending lines denote adjacent values (i.e., the most extreme values within 1.5 interquartile range of the 25 th and 75 th percentile of each group) 
most recent studies on combined implant/lipofilling approach continue to show satisfactory results.

The explanation for the lower rate of capsular contracture provided by fat grafting has not yet been answered. Won-Serk et al. underlined how adipose stem cells lead to an increase in fibroblasts and their stimulation with increased collagen production of type 1 and fibronectin. Their results showed a beneficial effect of adipose stem cell treatment on wound healing in mice and the absence of a significant number of inflammatory cells in the dermis of wounds [47]. Reduction in the number of cells with chronic inflammation cells may be one of the factors contributing to the reduced capsular contracture rate.

By using a validated survey tool (BREAST-Q), in this study, we show that patient of group 2 were significantly more satisfied with the appearance of their breast and showed an improved psychosocial, sexual, and physical well-being than patients exposed to prosthetic reconstruction alone.

As already reported by other authors [31, 48, 49], fat grafting provides a significant analgesic effect in patients who underwent an implant-based breast reconstruction.

The current study is not exempt from limitations and mainly represented by the relatively small size of the examined sample, short follow-up, and clinical and radiological evaluations that are highly physician-dependent, and its retrospective design.

\section{Conclusions}

The HBR protocol is associated with a lower rate of capsular contracture, less breast pain at long follow-up times, and a lower overall rate of revision surgery compared to standard expander-implant reconstruction. A specific cost analysis could further clarify the advantages of this protocol vs. a standard procedure.

Acknowledgments We thank Rossella Cimarosti, MD, for her time and support with this work.

Funding information This research did not receive any specific grant from funding agencies in the public, commercial, or not-for-profit sectors.

\section{Compliance with ethical standards}

Conflict of interest The authors declare that they have no conflicts of interest.
Ethical approval Our institutional ethics committee (Comitato Etico Unico Regionale C.E.U.R - EGAS, Udine, Italy) approved the study design. Data is available at Research Registry under accession number: Researchregistry 3592.

Informed consent A written informed consent was obtained from all patients in the study.

Open Access This article is distributed under the terms of the Creative Commons Attribution 4.0 International License (http:// creativecommons.org/licenses/by/4.0/), which permits unrestricted use, distribution, and reproduction in any medium, provided you give appropriate credit to the original author(s) and the source, provide a link to the Creative Commons license, and indicate if changes were made.

\section{References}

1. Neuber F (1983) Fat transplantation. Chir Kongr Verhandl Dsch Gesellch Chir 20:66

2. Guthrie D (1928) Fat grafting in mastoid surgery. Proc R Soc Med 12:1914-1917

3. Fournier P (1991) Liposculpture: the syringe technique. Arnette Blackwell, Paris, pp 265-266

4. Roddi R, Riggio E, Gilbert PM, Hovius SE, Vaandrager JM, Van Der Meulen JC (1994) Clinical evaluation of techniques used in the surgical treatment of progressive hemifacial atrophy. J Craniomaxillofac Surg 1:23-32

5. Agha RA, Fowler AJ, Pidgeon TE, Wellstead G, Orgill DP, VOGUE Steering Group (2016) Protocol for the development of a core outcome set for autologous fat grafting to the breast. Int $\mathrm{J}$ Surg 31:104-106

6. Wan D, Rohrich RJ (2016) Revisiting the management of capsular contracture in breast augmentation: a systematic review. Plast Reconstr Surg 137:826-841

7. Ueberreiter K, Tanzella U, Cromme F, Doll D, Krapohl BD (2013) One stage rescue procedure after capsular contracture of breast implants with autologous fat grafts collected by water assisted liposuction ("BEAULI Method"). GMS Interdiscip Plast Reconstr Surg DGPW 2: Doc03

8. Datta G, Manfia A, Nicolò FA et al (2019) Total breast reconstruction with fat graft after serial expander deflation: a case series. Eur J Plast Surg. https://doi.org/10.1007/s00238-019-01526-w

9. Zingaretti N, De Lorenzi F, Dell'Antonia F et al (2016) The use of precapsular space in secondary breast reconstruction. Aesthet Plast Surg 40:716-723

10. Yoshimura K, Asano Y, Aoi NN, Kurita M, Oshima Y, Sato K, Inoue K, Suga H, Eto H, Kato H, Harii K (2010) Progenitorenriched adipose tissue transplantation as rescue for breast implant complications. Breast J 16:169-175

11. Del Vecchio DA (2012) "SIEF"-simultaneous implant exchange with fat: a new option in revision breast implant surgery. Plast Reconstr Surg 130:1187-1196 
12. Auclair E, Blondeel P, Del Vecchio D (2013) Composite breast augmentation: soft-tissue planning using implants and fat. Plast Reconstr Surg 132:558-568

13. Rietjens M, De Lorenzi F, Rossetto F et al (2011) Safety of fat grafting in secondary breast reconstruction after cancer. J Plast Reconstr Aesthet Surg 64:477-483

14. Waked K, Colle J, Doornaert M, Cocquyt V, Blondeel P (2017) Systematic review: the oncological safety of adipose fat transfer after breast cancer surgery. Breast 31:128-136

15. Semprini G, Cattin F, Vaienti L, Brizzolari M, Cedolini C, Parodi PC (2013) Oncoplastic surgery and cancer relapses: cosmetic and oncological results in 489 patients. Breast 22:946-951

16. Petit JY, Botteri E, Lohsiriwat V, Rietjens M, de Lorenzi F, Garusi C, Rossetto F, Martella S, Manconi A, Bertolini F, Curigliano G, Veronesi P, Santillo B, Rotmensz N (2012) Locoregional recurrence risk after lipofilling in breast cancer patients. Ann Oncol 23:582588

17. Kronowitz SJ, Mandujano CC, Liu J, Kuerer HM, Smith B, Garvey P, Jagsi R, Hsu L, Hanson S, Valero V (2016) Lipofilling of the breast does not increase the risk of recurrence of breast cancer: a matched controlled study. Plast Reconstr Surg 137:385-393

18. Domenis R, Lazzaro L, Calabrese S, Mangoni D, Gallelli A, Bourkoula E, Manini I, Bergamin N, Toffoletto B, Beltrami CA, Beltrami AP, Cesselli D, Parodi P (2015) Adipose tissue derived stem cells: in vitro and in vivo analysis of a standard and three commercially available cell-assisted lipotransfer techniques. Stem Cell Res Ther 6:2

19. Oranges CM, Striebel J, Tremp M, Madduri S, Kalbermatten DF, Schaefer DJ (2018) The impact of recipient site external expansion in fat grafting surgical outcomes. Plast Reconstr Surg Glob Open 6: e1649

20. Khouri RK Jr, Khouri RE, Lujan-Hernandez JR et al (2014) Diffusion and perfusion: the keys to fat grafting. Plast Reconstr Surg Glob Open 2:e220

21. Zanin C, Calabrese S, Rampino Cordaro E et al (2017) Chronological order of lipofilling during implant exchange. Plast Reconstr Surg glob open 25(5):e1307

22. Gentile P, Scioli MG, Orlandi A et al (2015) Breast reconstruction with enhanced stromal vascular fraction fat grafting: what is the best method? Plast Reconstr Surg glob open 8(3):e406

23. Condè-Green A, Kotamarti VS, Sherman LS et al (2016) Shift toward mechanical isolation of adipose-derived stromal vascular fraction: review of upcoming techniques. Plast Reconstr Surg Glob Open 4:e1017

24. Spear S, Coles C, Leung B et al (2016) The safety, effectiveness, and efficiency of autologous fat grafting in breast surgery. Plast Reconstr Surg Glob Open 4:e827

25. Debald M, Pech T, Kaiser C, Keyver-Paik MD, WalgenbachBruenagel G, Kalff JC, Kuhn W, Walgenbach KJ (2017) Lipofilling effects after breast cancer surgery in post-radiation patients: an analysis of results and algorithm proposal. Eur J Plast Surg 40:447-454

26. Calabrese S, Zingaretti N, Zanin C, Fin A, Mura S, Parodi PC (2018) Hybrid breast reconstruction: preliminary report. Plast Reconstr Surg Glob Open 6:e1660

27. Agha RA, Borrelli MR, Vella-Baldacchino M, Thavayogan R, Orgill DP, Pagano D, Pai PS, Basu S, McCaul J, Millham F, Vasudevan B, Leles CR, Rosin RD, Klappenbach R, MachadoAranda DA, Perakath B, Beamish AJ, Thorat MA, Ather MH,
Farooq N, Laskin DM, Raveendran K, Albrecht J, Milburn J, Miguel D, Mukherjee I, Valmasoni M, Ngu J, Kirshtein B, Raison N, Boscoe M, Johnston MJ, Hoffman J, Bashashati M, Thoma A, Healy D, Orgill DP, Giordano S, Muensterer OJ, Kadioglu H, Alsawadi A, Bradley PJ, Nixon IJ, Massarut S, Challacombe B, Noureldin A, Chalkoo M, Afifi RY, Agha RA, Aronson JK, Pidgeon TE (2017) The STROCSS statement: strengthening the reporting of cohort studies in surgery. Int J Surg 46:198-202

28. Malahias M, Jordan DJ, Hughes LC, Hindocha S, Juma A (2016) A literature review and summary of capsular contracture: an ongoing challenge to breast surgeons and their patients. Int J of Surg Open 3: $1-7$

29. Selkow NM, Pietrosimone BG, Saliba SA (2011) Subcutaneous thigh fat assessment: a comparison of skinfold calipers and ultrasound imaging. J Athl Train 46:50-54

30. Pusic AL, Klassen AF, Scott AM, Ja K, Cordeiro PG, Cano SJ (2009) Development of a new patient-reported outcome measure for breast surgery: the BREAST-Q. Plast Reconstr Surg 124:345353

31. Cogliandro A, Barone M, Tenna S, Coppola MM, Persichetti P (2016) The role of lipofilling after breast reconstruction: evaluation of outcomes and patient satisfaction with breast-Q. Aesthet Plast Surg 41:1325-1331

32. Barone M, Cogliandro A, Grasso A, Altomare V, Persichetti P (2018) Patient's breast perception after mastectomy: analysis of outcomes in 208 patients with Breast-Q following mastectomy alone, implant of tissue expander and definitive breast reconstruction. Plast Reconstr Surg 142:89e-91e

33. Sarfati I, Ihrai T, Kaufman G, Nos C, Clough KB (2011) Adiposetissue grafting to the post-mastectomy irradiated chest wall: preparing the ground for implant reconstruction. J Plast Reconstr Aesthet Surg 64:1161-1166

34. Salgarello M, Visconti G, Barone-Adesi L (2012) Fat grafting and breast reconstruction with implant: another option for irradiated breast cancer patients. Plast Reconstr Surg 129:317-329

35. Ribuffo D, Atzeni M, Guerra M, Bucher S, Politi C, Deidda M, Atzori F, Dessi M, Madeddu C, Lay G (2013) Treatment of irradiated expanders: protective lipofilling allows immediate prosthetic breast reconstruction in the setting of postoperative radiotherapy. Aesthet Plast Surg 37:1146-1152

36. Panettiere P, Marchetti L, Accorsi D (2009) The serial free fat transfer in irradiated prosthetic breast reconstructions. Aesthet Plast Surg 33:695-700

37. Salgarello M, Visconti G, Farallo E (2010) Autologous fat grafting in radiated tissue prior to alloplastic reconstruction of the breast: report of two cases. Aesthet Plast Surg 34:5-10

38. Serra-Renom JM, Muñoz-Olmo JL, Serra-Mestre JM (2010) Fat grafting in postmastectomy breast reconstruction with expanders and prostheses in patients who have received radiotherapy: formation of new subcutaneous tissue. Plast Reconstr Surg 125:12-18

39. Serratore F, Guerra M, Bucher S, Lay G, Ribuffo D (2015) Outcomes of protective lipofilling on post-mastectomy radiotreated patients in immediate expander-implant breast reconstruction. ESJO 41:S5

40. Pompei S, Arelli F, Labardi L, Marcasciano F, Caravelli G, Cesarini C, Abate O (2012) Breast reconstruction with polyurethane implants: preliminary report. Eur J Plast Surg 35:441-447 
41. Pompei S, Arelli F, Labardi L, Marcasciano F, Evagelidou D, Ferrante G (2016) Polyurethane implants in 2-stage breast reconstruction: 9-year clinical experience. Aesthet Surg J 37:171-176

42. Sommeling CE, Van Landuyt K, Depypere H et al (2017) Composite breast reconstruction: implant-based breast reconstruction with adjunctive lipofilling. J Plast Reconstr Aesthet Surg 70: $1051-1058$

43. Stillaert FB, Sommeling C, D'Arpa S et al (2016) Intratissular expansion-mediated, serial fat grafting: a step-by-step working algorithm to achieve $3 \mathrm{D}$ biological harmony in autologous breast reconstruction. J Plast Reconstr Aesthet Surg 69:1579-1587

44. Fabiocchi L, Semprini G, Cattin F, Dellachiesa L, Fogacci T, Frisoni G, Samorani D (2017) "Reverse expansion": a new technique of breast reconstruction with autologous tissue. J Plast Reconstr Aesthet Surg 70:1537-1542

45. Nava MB, Catanuto G, Rocco N (2018) Hybrid breast reconstruction. Minerva Chir 73:329-333

46. Rigotti G, Marchi A, Galiè M et al (2007) Clinical treatment of radiotherapy tissue damage by lipoaspirate transplant: a healing process mediated by adipose-derived adult stem cells. Plast Reconstr Surg 119:1409-1422

47. Kim WS, Park BS, Sung JH, Yang JM, Park SB, Kwak SJ, Park JS (2007) Wound healing effect of adipose-derived stem cells: a critical role of secretory factors on human dermal fibroblasts. J Dermatol Sci 48:15-24

48. Caviggioli F, Maione L, Forcellini D, Klinger F, Klinger M (2011) Autologous fat graft in postmastectomy pain syndrome. Plast Reconstr Surg 128:349-352

49. Maione L, Vinci V, Caviggioli F, Klinger F, Banzatti B, Catania B, Lisa A, Klinger M (2014) Autologous fat graft in postmastectomy pain syndrome following breast conservative surgery and radiotherapy. Aesthet Plast Surg 38:528-532

Publisher's note Springer Nature remains neutral with regard to jurisdictional claims in published maps and institutional affiliations. 